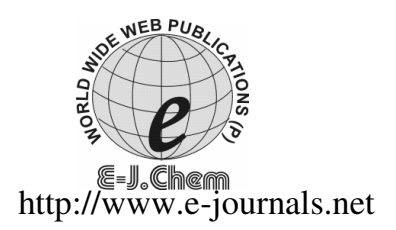

ISSN: 0973-4945; CODEN ECJHAO
E-Journal of Chemistry
$2011, \mathbf{8}(\mathbf{4}), 1638-1643$

\title{
Preparation of Tannin Based Hydrogel for Biological Application
}

\author{
R. JAMEEL MHESSN, L. ABD-ALREDHA, \\ R. AL-RUBAIE* and A. FUAD KHUDAIR AZIZ \\ Department of Pharmaceutical Chemistry \\ Pharmacy College, Basrah University, Iraq \\ leaqaa2000@yahoo.com
}

Received 1 January 2011; Accepted 28 February 2011

\begin{abstract}
Polymeric blends as potential wound dressing were prepared. Natural polymer (Tannin) and synthetic polymers (PVA and PEG) were used to prepare heterogeneous blends. The product was identified by spectrophotometry. A diaphragm cell was used to measure the diffusion coefficient (D). The result shown the PEG-PVA disk was very faster permeability for all solution. The D of PVA/ PEG-Tannin blend was $0.184 \times 10^{-3} \mathrm{~cm}^{2} / \mathrm{s}$ higher than Tannin-PEG blend was $0.038 \times 10^{-3} \mathrm{~cm}^{2} / \mathrm{s}$. The natural phenolic compounds that can be used artificial membrane to inhibit growth or kill microorganism such as bacteria or fungi.
\end{abstract}

Keywords: Polymeric blend, Tannin, Diffusion Coefficient (D), PVA and PEG

\section{Introduction}

A wound dressing is applied to stop bleeding, absorbs exudates, ease pain and facilitate epider resurfacing. Generally the type of dressing used in particular situation is based on its adhesiveness and transparency ${ }^{1}$. A variety of biological polymers including collagen, fibrin, fibronectin and hyaluronic acid have been studied as dressings for dermal wounds. Unlike synthetic polymers, which at the very best as inert coverings for the wound, biological polymers have unique properties that play a role in normal wound healing. Synthetic polymers can be easily manufactured using conventional technology into films, fibers, sheets and sponges. For this reason these materials received attention as potential wound dressings for deep wounds. The natural polymers have been developed for biomedical applications ${ }^{2}$. Polymeric blends are produced by physical mixing of two or more existing polymers. It is a convenient route to develop new polymeric materials, which combine the properties of more than one existing polymer. A wide range of material properties can be obtained by changing the blend composition. Polymer blends are either homogeneous or heterogeneous. In homogeneous blends, both blend components lose part of their identity 
and the final properties usually are the arithmetical average of both blend components. In heterogeneous blends, on the other hand, the properties of all blend components are present ${ }^{3}$. The hydrophilic property of polymers were used to modify the surfaces of catheter materials with reduced bacterial adhesion and less encrustation. The adherence of hydrophobic enterococcus faecalis isolate to the polyvinyl pyrrolidone (PVP) coated polyurethane was significantly less than adherence to uncoated polyurethane ${ }^{4}$. Tannins are polyphenolic compounds have defence mechanism against insects and microbes by binder to extracellular polymer, causing substrate and ion deprivation and by inhibiting enzymes ${ }^{5}$. The dressings are used as coverings for deep (full-thickness) burns and skin ulcers. In this applications synthetic polymeric dressings create an inert environment that controls water and passage from the wound while preventing bacterial infiltration ${ }^{6}$.

The goal of use natural phenollic compounds topically to inhibit or kills microorganism such bacteria, fungi. Polyphenolic compounds (Tannins) were extracted from different part of plants. It can be used on biological activity against fungi (used cultures of Gliocladium reseum) ${ }^{7}$.

The essential oil and phenolic acid extracts of pepper fruit inhibited the growth of tomato rot fungi. Extracts of higher plants contain a variety of phenolics and essential oil that are inhibitory to microorganisms ${ }^{8}$.

\section{Experimental}

Two-necked flask equipped with mechanical stirrer and condenser, was charged with $(0.44 \mathrm{~g}$, $0.01 \mathrm{~mol}$ ) of PEG (Polyethylene glycol) dissolved in $10 \mathrm{~mL}$ water, $0.5 \mathrm{~mL}$ of diluted $\mathrm{H}_{2} \mathrm{SO}_{4}$ $(10 \%)$ and $(0.45 \mathrm{~g}, 0.01 \mathrm{~mol})$ of PVA (Polyvinyl alcohol). The mixture was refluxed with vigorous stirring. The reaction was continued for $1 \mathrm{~h}$ then cooled and neutralized by $10 \%$ $\mathrm{NaHCO}_{3}$ and the solvent was evaporated. The product was dissolved in ethanol and filtered to remove the salt. The care was taken to eliminate entrapment of air bubbles during mixture was used to obtain a membrane by the conventional solution casting method at room temperature.

\section{Preparation of PEG-Tannin blend}

( $2.98 \mathrm{~g}, 0.01 \mathrm{~mol})$ of Tannic acid was dissolved in $10 \mathrm{~mL}$ water in tow-necked flask, then solution $(0.44 \mathrm{~g}, 0.01 \mathrm{~mol})$ of PEG in $10 \mathrm{~mL}$ water was added. The reaction mixture was refluxed for $1 \mathrm{~h}$ with vigorously mechanical stirred, then cool and the solvent was evaporated at room temperature to obtain a membrane.

\section{Preparation of PVA-PEG-Tannin blend}

$(0.89 \mathrm{~g}, 0.01 \mathrm{~mol})$ of blend was dissolved in $10 \mathrm{~mL}$ water, after complete dissolve, $(2.98 \mathrm{~g}$, $0.01 \mathrm{~mol}$ ) of tannin was added with mechanical stirring. The mixture was refluxed for $1 \mathrm{~h}$ then cooled and the solvent was evaporated at room temperature. The membrane was obtained by the conventional casting method at room temperature.

Measurment of diffusion coefficient $(D)^{9}$

A diaphragm cell shown in (Figure 1) was used to measure the diffusion coefficient. The cell consisted of two chambers separated by the hydrogel $(\approx 0.2-\mathrm{mm}$ thick). The first chamber, donor, contained $5 \mathrm{~mL}$ of SA solution in water $(1.6 \mathrm{mg} / \mathrm{mL})$. The other chamber consisted of distilled water (receptor). The system was placed in a constant temperature water bath.

A pipette was used to draw $0.1 \mathrm{~mL}$ sample from donor and $1.0 \mathrm{~mL}$ sample from the receptor compartment periodically. The samples withdrawn were replaced by same amount of distilled water. The samples were analyzed by acidic ferric chloride solution at $(\lambda=450 \mathrm{~nm})$ to determine the concentration of SA in each chamber as a function of time. The diffusion coefficient (D) of the drug through the hydrogel was calculated. 


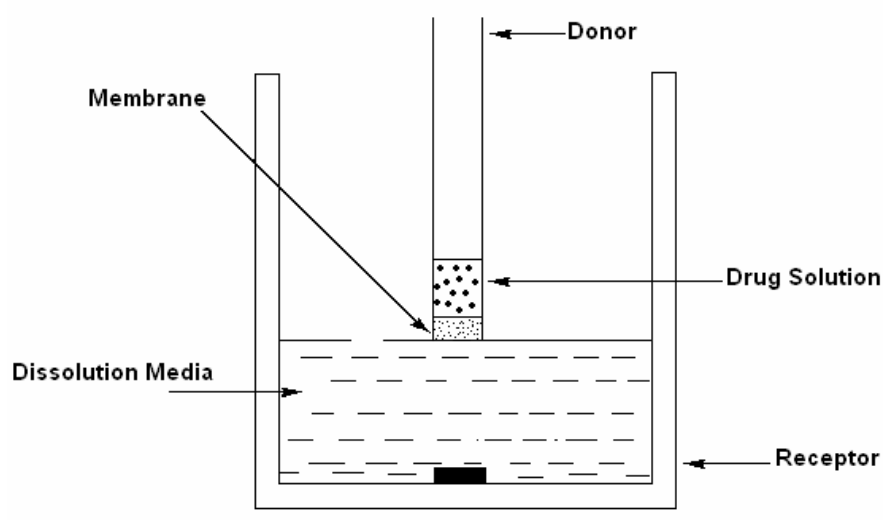

Figure 1. Diaphragm cell used to measure diffusion coefficient (D)

\section{Results and Discussion}

Biodegradable polymeric materials have been used in medicine with the major purpose to assist damaged tissues for their healing. The most accepted application is wound closure by absorbable sutures ${ }^{10}$. A marked advantage of collagen over synthetic biodegradable polymers is its high affinity to fibroblast, leading to accelerated regeneration of tissues. Yannas et.al. ${ }^{11}$ have reported that the artificial skin made of a porous collagen sheet exhibited excellent regeneration of skin tissues.

The composition of the PVA/PEG copolymer, PVA/Tannin and copolymer/Tannin were evaluated by FT.IR Spectroscopy by $\mathrm{KBr}$ disk in $500-4000 \mathrm{~cm}^{-1}$ region. The free $\mathrm{OH}$ vibration occurs as a sharp IR peak at above $3600 \mathrm{~cm}^{-1}$.

The $\mathrm{OH}$ peak is broadened and shifted to $3500-2500 \mathrm{~cm}^{-1}$ due to various types of hydrogen bond formation and the interaction can be intermolecular, intramolecular or both. As a result of formation of hydrogen bonds, the stretch peak of $\mathrm{OH}$ shifts to lower frequency from the unassociated sharp absorption at $3600 \mathrm{~cm}^{-1}$. The peaks at $1450 \mathrm{~cm}^{-1}$ and $1340 \mathrm{~cm}^{-1}$ are C-O-H bend peaks, while the intense peak at $1090-1085 \mathrm{~cm}^{-1}$ is C-C-O stretch peak, as shown in (Table 1). The main propose of this research was to develop a polymer system which can be used as biomedical devices, especially as artificial skin ${ }^{12}$.

Table 1. The important FT.IR bands of products

\begin{tabular}{cccccc}
\hline \multirow{2}{*}{ Products } & \multicolumn{5}{c}{ Absorption of bands, $\mathrm{cm}^{-1}$} \\
\cline { 2 - 6 } & $\mathrm{C}-\mathrm{O}-\mathrm{H}$ & $\mathrm{C}=\mathrm{C} \mathrm{Ar}$ & $\mathrm{C}=\mathrm{O}$ & $\mathrm{CH}_{3}, \mathrm{CH}_{2}$ & $\mathrm{OH}$ \\
\hline PVA-PEG & $1450-1375$ & --- & 1733 & $2900-3199$ & --- \\
Tannin- PEG & $1370-1450$ & 1616 & 1735 & $2930-3170$ & 3450 \\
PVA-PEG-Tannin & $1450-1340$ & 1616 & 1701 & $2931-3170$ & 3460 \\
\hline
\end{tabular}

(Figures 2 and 3) shows a typical variations of the concentration of SA in the two chambers. As can be expected, the concentration of SA in donor decreases, over time while there is a corresponding increase in concentration in receptor expect PVA/PEG gel. The PVA/PEG membrane was permeable for all solution after few minutes may be due to linearity hydrophilicity of polymer. At any time, $t$, the concentration values were used to calculate the diffusion coefficient $[\mathrm{D}]$, from the following equation:

$$
\mathrm{D}=1 / \mathrm{B}^{*} \ln \left[\mathrm{C}_{\mathrm{R}}(\mathrm{t})-\mathrm{C}_{\mathrm{D}}(\mathrm{t}) / \mathrm{C}_{\mathrm{R}}(\mathrm{o})-\mathrm{C}_{\mathrm{D}}(\mathrm{o})\right], \beta=\mathrm{A}_{\mathrm{H}} / \mathrm{W}_{\mathrm{H}}{ }^{*}\left[1 / \mathrm{V}_{1}+1 / \mathrm{V}_{2}\right]
$$




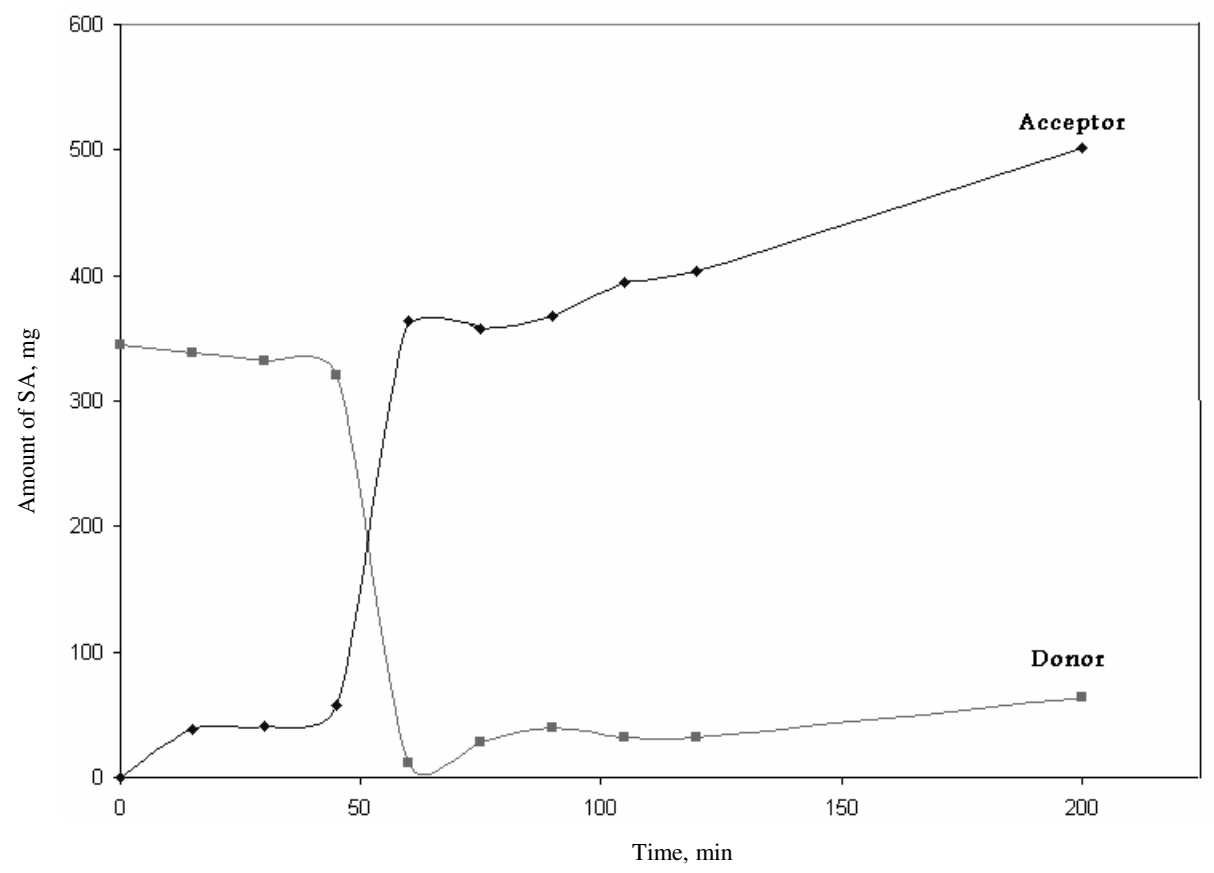

Figure 2. Effect of time of permability of SA in donor and receptor (PEG-PVA/ Tannin membrane)

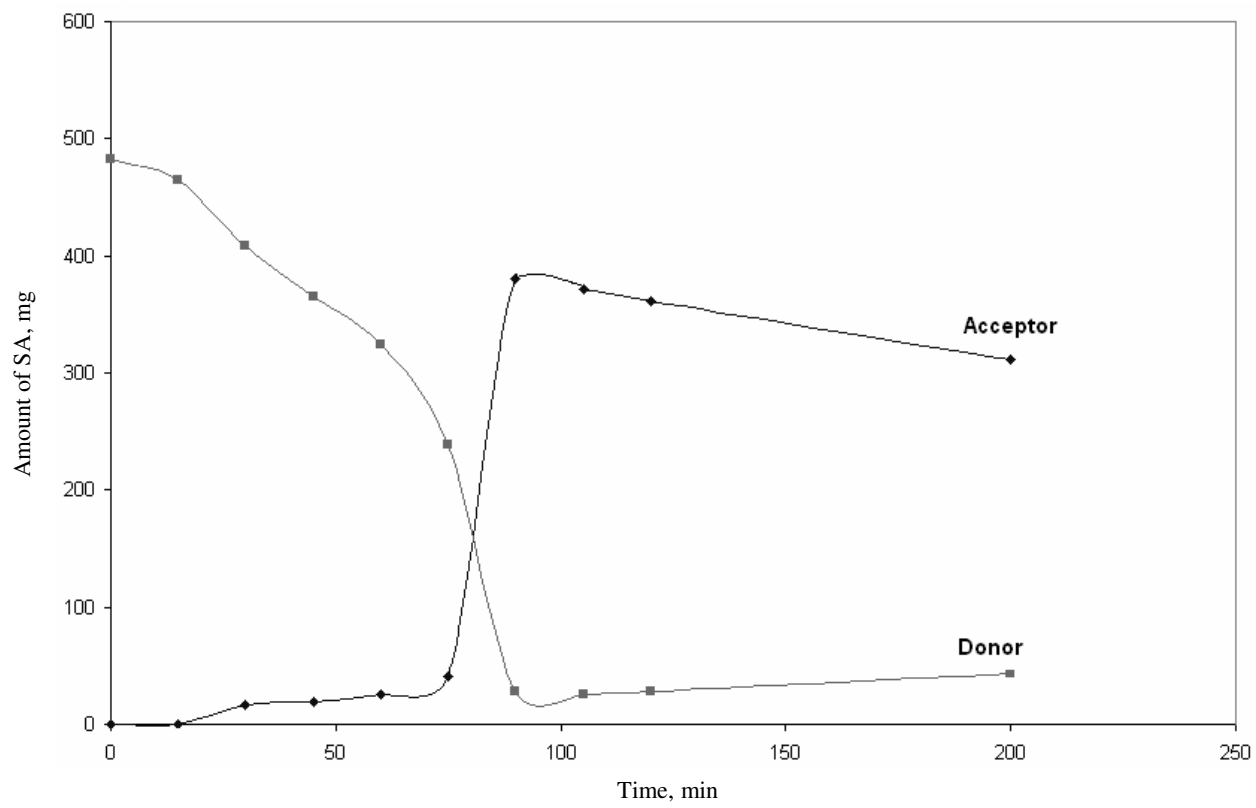

Figure 3. Effect of time of permeability of SA in donor and (PEG-Tannin membrane)

Where $C_{D}, C_{R}=$ concentration of SA in donor and receptor at initial $C(0)$ and after time $\mathrm{t}, \mathrm{C}(\mathrm{t}) . \mathrm{A}_{\mathrm{H}}=$ effective cross-sectional area and diffusion in the hydrogel samples; $\mathrm{W}_{\mathrm{H}}=$ width of the hydrogel sample and $\mathrm{V}=$ volume of SA solution in receptor and volume of dissolution 
media in receptor.(Figures 4 and 5) shows plot of $\ln X v s$. time, whose slope was used for determining diffusion coefficient [D]. The D of SA through the PEG-Tannin hydrogel membrane was found to be $0.038 \times 10^{-3} \mathrm{~cm}^{2} / \mathrm{s}$. While the D of SA through the PVA-PEGTannine membrane was found to be $0.184 \times 10^{-3} \mathrm{~cm}^{2} / \mathrm{s}$. The larger D of PVA-PEG/Tannin blend due to more hydrophilicity of this membrane compare with PEG/Tannin membrane ${ }^{9}$. The membrane could be tried as artificial skin and various nutrients/ healing factors and medicaments can be delivered directly to the wound surface by putting a swab/hydrophilic matrix.

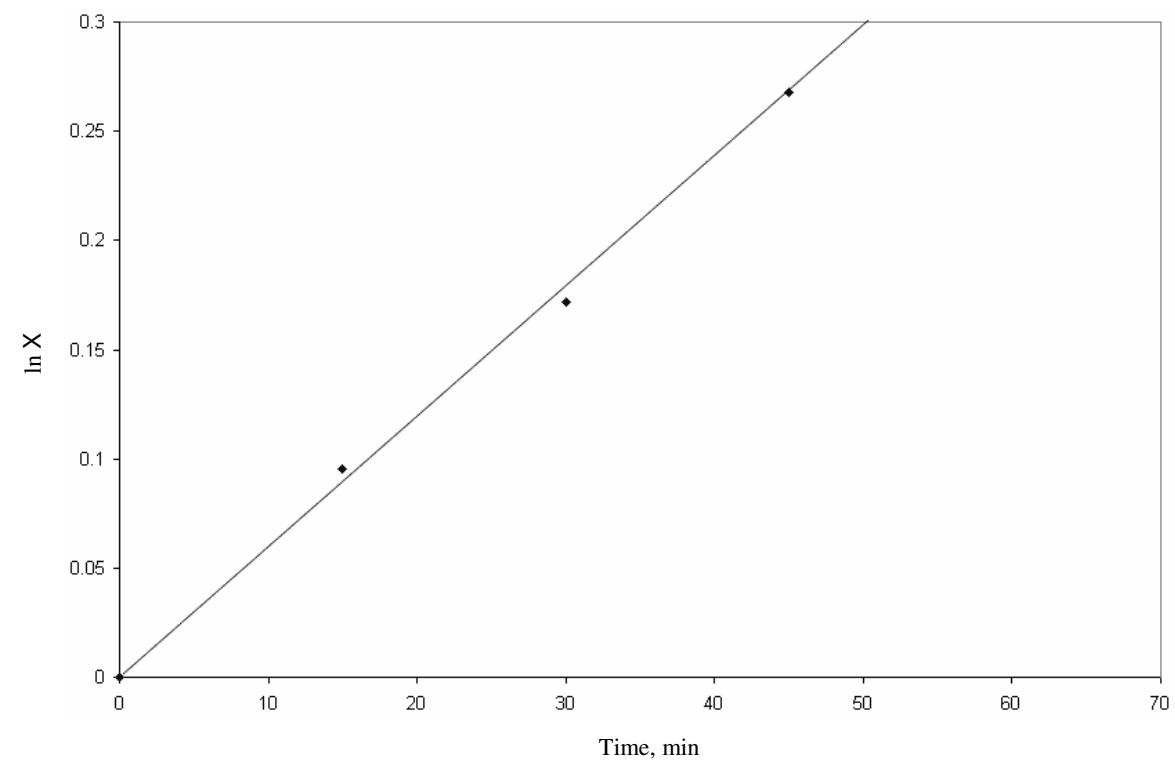

Figure 4. Represent calculation of diffusion coefficient (D) of PEG-Tannin

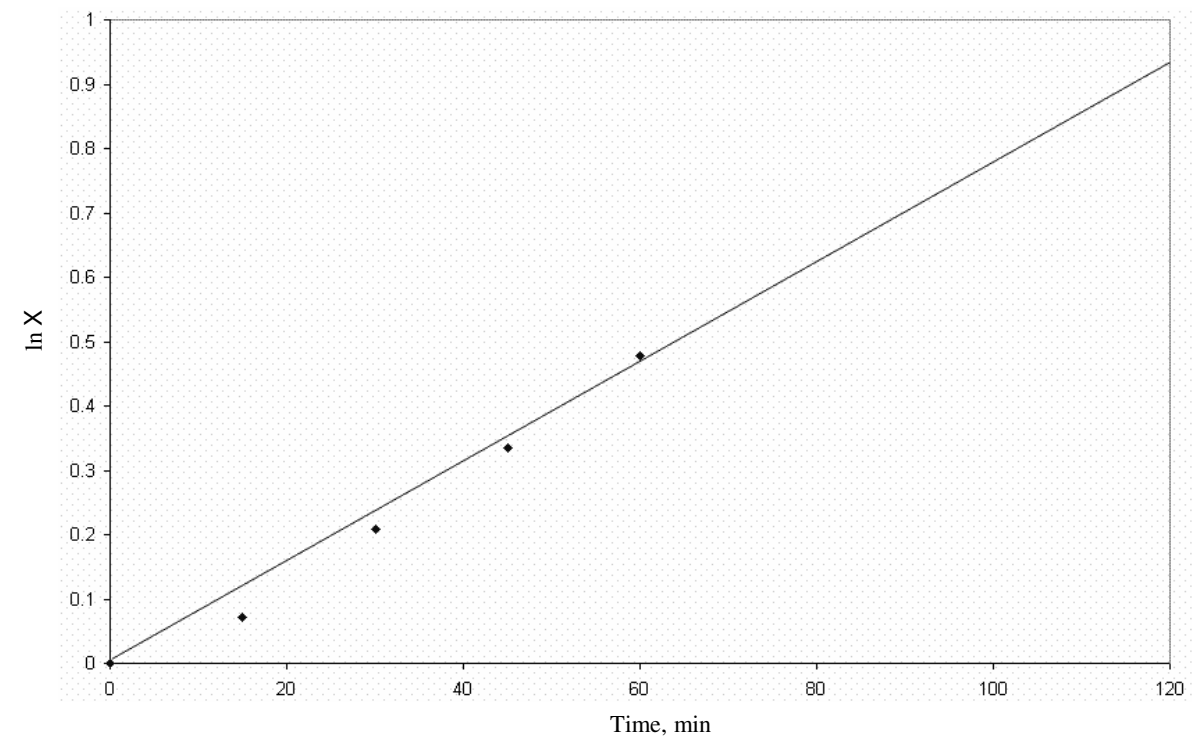

Figure 5. Represent calculation of diffusion coefficient (D) for PEG/PVA-Tannin 


\section{Conclusion}

Membrane obtained by formation of strong hydrogen bond between the chains. The FT-IR spectra showed the formation of ester linkage. The diffusion coefficient, D of SA through the polymeric blends membrane. The diffusion coefficient of PEG/PVA-Tannin membrane was found to be $0.184 \times 10^{-3} \mathrm{~cm}^{2} / \mathrm{s}$ while the D of PEG-Tannin membrane was found to be $0.038 \times 10^{-3} \mathrm{~cm}^{2} / \mathrm{s}$.

\section{References}

1. Joanna Briggs Institute, Best Practice. Split thickness skin graft donor sites: Post Harvest Management Australia, 2002, 6(2), 1329.

2. Plank H, Dauner M and Renardy M, Springer-Verlag (Berlin, New York), 1992, 3-54, 196.

3. Koning C, Duin M V, Pagnoulle C and Jerome R, Prog Polym Sci., 1998, 23, 707-757.

4. Tunney M M and Gorman S P, Biomat., 2002, 23, 4601-4608.

5. Nelson K E, Thonney M L, T K, Zinder S H and Pell A N, Appl Environ Microbial., 1998, 64, 3824-3830.

6. $\quad$ Sangecta N B and Christophers C S. J Biomed Microdevices., 1999, 2, 131-144.

7. Schroers H J, Samuels G J, Seifert K A and Gams W, Mycologia., 1999, 91,365-385.

8. Ejechi B O and Akpomedaye DE, Afr J Biotech., 2005, (4)3, 258-261.

9. Kunal P, Banthia A K and Majumdar D K, Afr J Biomed Res., 2006, 9, 23-29.

10. Ikada Yannas, Handbook of fiber science and technology, Part B Ed. Marcel Deklcer, USA, 1989, III, 253.

11. Ikada Yannas, Medical application of biodegradable polymers and Fong $\mathrm{H}$. Biomaterials, Editors, Elsevier science Publishers B.V.1991. I

12. Mulder G D and Vande Berg J S, J Am Podiatr Med Assoc., 2002, 92(1), 34-47. 


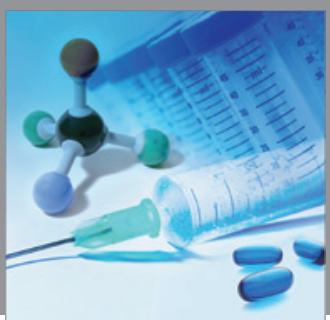

International Journal of

Medicinal Chemistry

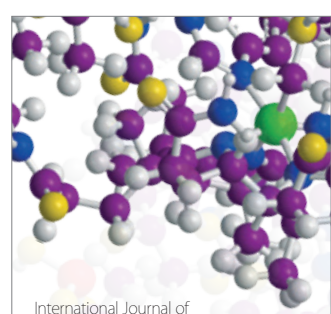

Carbohydrate Chemistry

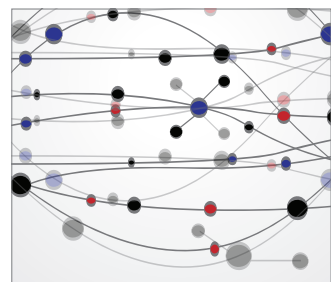

The Scientific World Journal
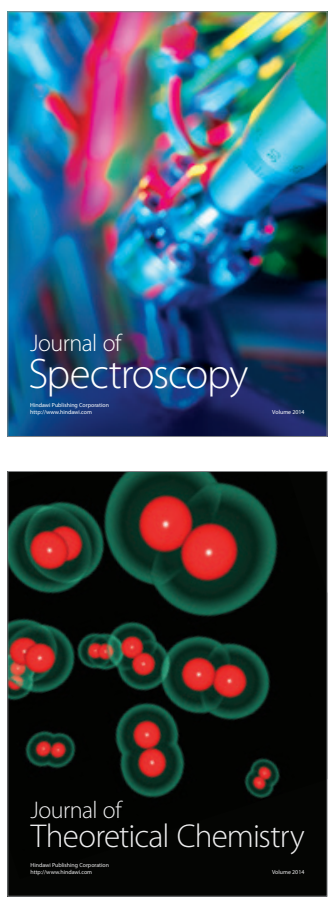
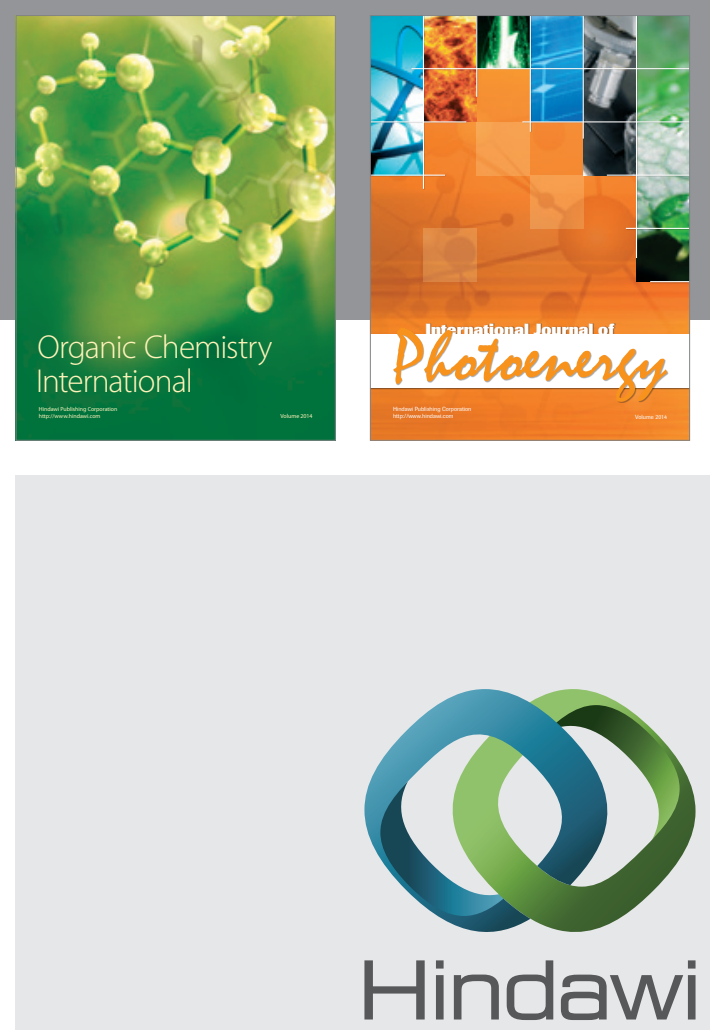

Submit your manuscripts at

http://www.hindawi.com
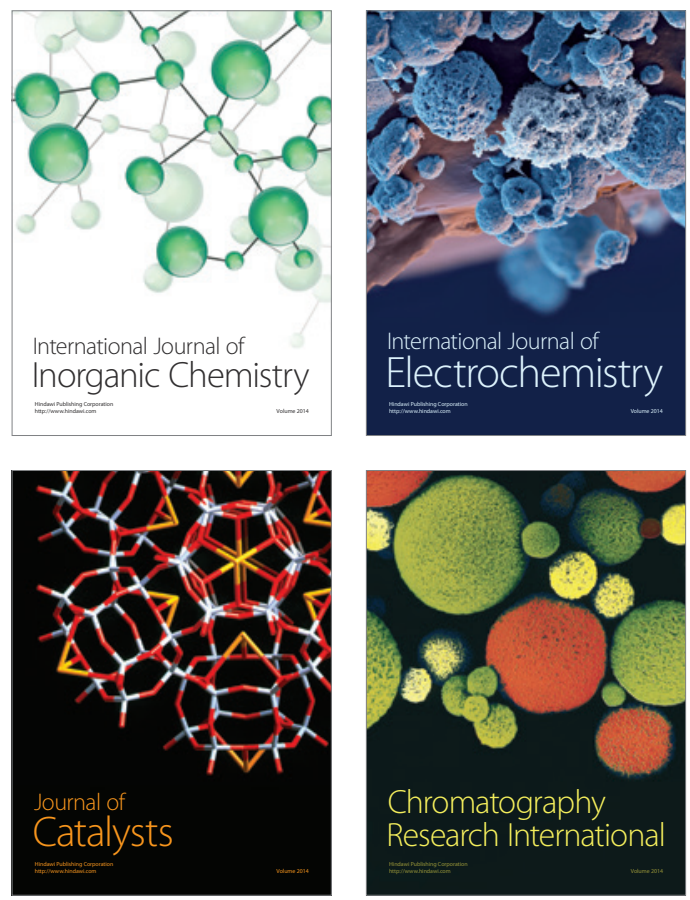
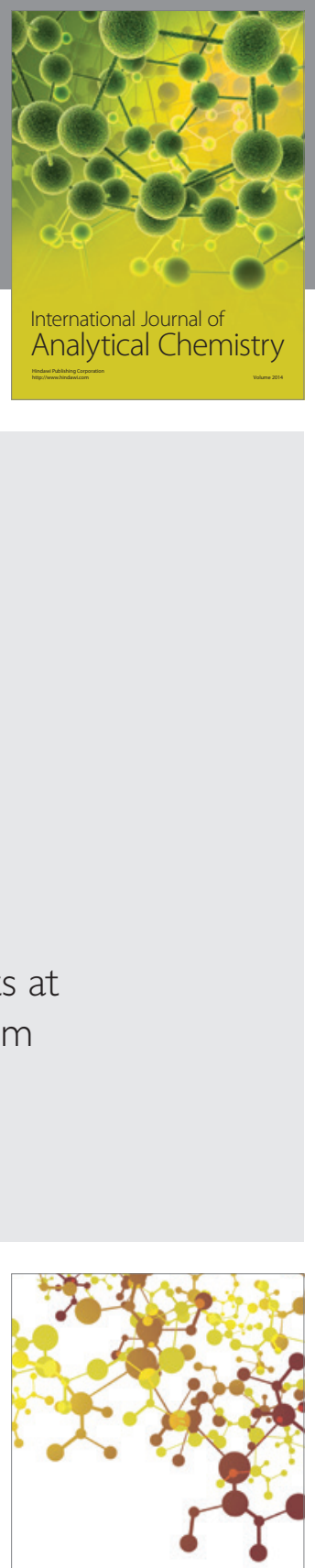

Journal of

Applied Chemistry
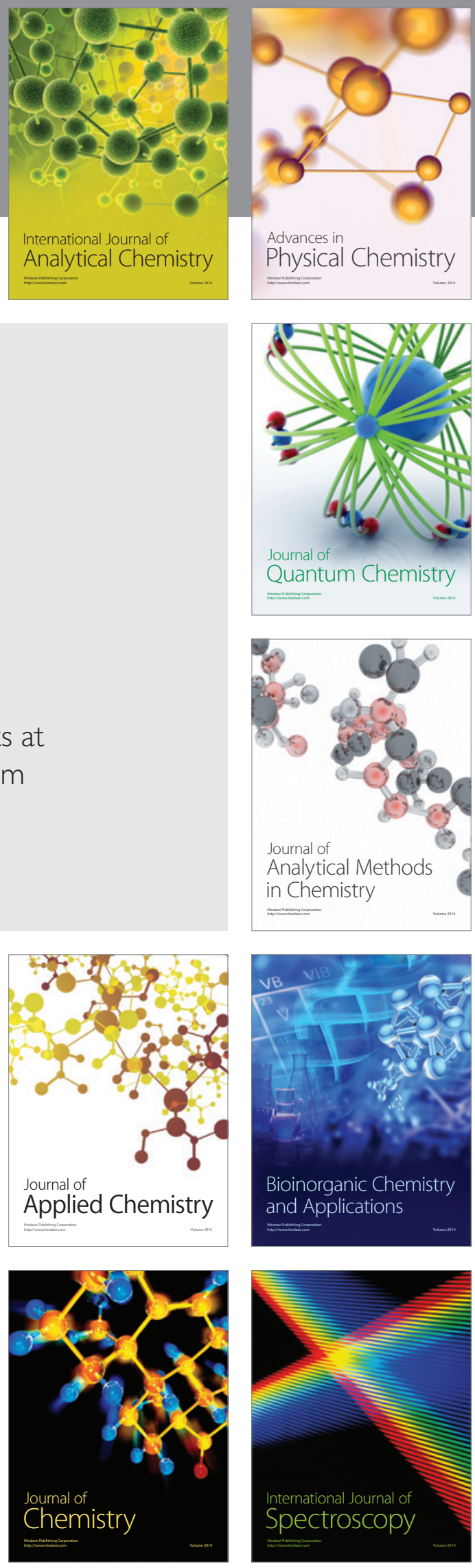